\title{
LA ACTIVIDAD PROBATORIA EN EL DELITO FUENTE DEL TIPO PENAL DE LAVADO DE ACTIVOS
}

Paulo César Ospitia Rozo*

\begin{abstract}
Resumen: La presente investigación desarrolla la problemática de la inexistencia de actividad probatoria para la acreditación del delito fuente que configura el tipo penal de lavado de activos. Se plantea que el dinamismo probatorio es condición de legitimidad y opera como garantía suprema del convencimiento judicial. La determinación judicial que acredite como cierta la ocurrencia de un hecho criminal -tipo penal- sin el ejercicio idóneo de la actividad probatoria, constituye una clara violación de principios y garantías fundamentales del proceso penal.

Palabras clave: Delito fuente, lavado de activos, prueba indiciaria, injerencia judicial, actividad probatoria, convencimiento judicial, principios, garantías, proceso penal, debido proceso.
\end{abstract}

Abogado egresado de la Universidad Colegio Mayor de Nuestra señora del Rosario, Candidato a Doctor en Derecho Universidad Nacional de Mar de Plata, Magíster en Derecho con profundización en Procesal Penal Universidad Sergio Arboleda en convenio con la Universidad Jaume I de España. Especialista en Ciencias Penales y Criminológicas, Universidad Externado de Colombia. Bogotá D.C., Colombia. Correo-e: ospitiapaulo@hotmail.com. Fecha de recepción: 10 de agosto de 2016. Fecha de modificación: 14 de noviembre de 2016. Fecha de aprobación: 24 de febrero de 2017. Para citar el artículo: OsPitia Rozo, PAulo CÉSAR. "La actividad probatoria en el delito fuente del tipo penal de lavado de activos", en Revista Derecho Penal y Criminología, Vol. 37, n. ${ }^{\circ} 103$, julio-diciembre de 2016, Bogotá: Universidad Externado de Colombia, pp. 145-169, DOI: https://doi.org/10.18601/01210483.v37N103.07 


\title{
EVIDITIARY ACTIVITY IN THE FELONY OF MONEY LAUNDERING
}

\begin{abstract}
This research develops the problem of the lack of evidence in order to source accreditation crime that configures the crime of money laundering. Here the evidence suggests that dynamism is a condition of legitimacy, operating as supreme guarantee of the judicial conviction. The judicial determination that proves to be true the occurrence of a penal type criminal act without the suitable exercise of evidential activity, constitutes a clear violation of fundamental principles and guarantees of criminal proceedings.

Keywords: money laundering, circumstantial evidence, court interference, legal conviction, guarantees, criminal procedure, due process.
\end{abstract}

\section{INTRODUCCIÓN}

Se entiende por lavado de activos el proceso de legalización de bienes de origen delictivo (Blanco Cordero, 1997, pp. 96-98). La doctrina penal universal concuerda en que la conducta de lavado de activos debe recaer sobre los recursos ilícitos procedentes de un delito fuente, también llamado previo.

Las distintas convenciones internacionales han estipulado que, en virtud de la autonomía del tipo penal de lavado de activos, este se puede concretar sin necesidad de la condena por el delito fuente -reflejada en sentencia condenatoria-, como consecuencia de la evolución de un proceso penal independiente al de lavado de activos. Es más, se sugiere que no se requiere el ejercicio pleno de la actividad probatoria con el fin de obtener el convencimiento judicial de la consumación del delito previo para sustentar responsabilidad penal por el tipo penal de lavado de activos.

En esta dirección, la jurisprudencia de la Corte Suprema de Justicia de Colombia -Sala de Casación Penal- ha sostenido la tesis según la cual no es necesaria la punición del delito fuente para condenar por lavado de activos. A falta de prueba directa, se acude a la prueba indiciaria, sosteniendo el criterio de que simplemente bastará una inferencia judicial fundada en prueba indiciaria para la acreditación del delito fuente y, así, condenar por el delito de lavado de activos.

Una limitada visión de la constitucionalización del proceso penal indicaría que la problemática de estos delitos se centra en cuál de los dos medios de prueba -prueba directa o prueba indiciaria- es idóneo para la acreditación del delito previo. Sin embargo, la génesis del verdadero problema radica en la total ausencia de exigencia probatoria para la comprobación del delito fuente del tipo penal de lavado de activos.

La perspectiva propia del derecho comparado enseña que el proceso penal está encaminado hacía la búsqueda de la verdad y versa sobre un objeto en particular: los 
hechos, los cuales, supuestamente, se encuadran en un tipo penal. Asimismo, el método penal acusatorio se desenvuelve al interior de un marco constitucional, que contiene una serie de principios y garantías fundamentales con incidencia en la actividad probatoria, buscando así que del acervo probatorio se desprenda un cierto grado de probabilidad que sustente el convencimiento judicial sobre los presupuestos fácticos que sostiene determinada hipótesis judicial (Morales Rivera, 2011, pp. 304 y ss.).

Considerando que el proceso penal persigue el develamiento de la verdad de la acusación preliminar y que el único medio aceptado para lograrlo es el elemento de prueba -que indica directa o indirectamente el conocimiento certero sobre el objeto del proceso-, sobresale la importancia de la actividad probatoria, entendida como aquella facultad que detentan los sujetos procesales para intervenir en la producción, formación, recepción y valoración del dato probatorio, para orientar la obtención del convencimiento judicial (Maier, 2012, pp. 848, 858-859; Cafferata Nores y Hairabedián, 2013, p.54).

A partir de estos presupuestos, se puede afirmar que la acreditación del delito fuente del delito de lavado de activos por medio de una inferencia judicial fundada en prueba indiciaria, sin la observancia de una actividad probatoria por parte de los sujetos procesales, es violatoria de los principios modulares y garantías sustanciales del debido proceso, e infringe además la estructura fundamental del procedimiento y las bases fundamentales del debido proceso (Bernal Cuéllar y Montealegre Lynnet, 2013b, pp. 968 y ss.).

Por consiguiente, esta investigación es relevante, en razón a que la valoración racional de la actividad probatoria es condición de legitimidad y opera como garantía suprema del convencimiento judicial, evitando así la arbitrariedad judicial (Morales Rivera, 2011, p. 428). La determinación judicial debe ser consecuencia del ejercicio de la actividad probatoria al interior del proceso y, a falta de esta, la inferencia judicial -con base en la prueba indiciaria no refutada- que debe hacer el juez para la acreditación del delito fuente del tipo penal de lavado de activos sería una presunción judicial, carente de cualquier tipo de certeza, con trasgresión del debido proceso penal. Claramente, la discusión propuesta es pertinente, pues se relaciona con la concepción jurídica de la sujeción del juez al marco constitucional y a su rol de garante del debido proceso penal, que fortalece la legitimidad de la jurisdicción penal (Ferrajoli, 2010, p. 26).

Con el fin de alcanzar los objetivos propuestos -a saber, demostrar la transgresión de principios y garantías fundamentales del debido proceso por la ausencia de actividad probatoria para la acreditación del delito fuente del tipo penal de lavado de activos, y que la actividad probatoria es el medio más idóneo para el convencimiento judicial-, se desarrollará un ejercicio analítico-deductivo, partiendo del concepto de lavado de activos, su relación con el delito fuente y la posición actual de la jurisprudencia de la Corte Suprema de Justicia -Sala Penal-sobre la prueba del delito fuente de 
lavado de activos. Estas son precisiones conceptuales necesarias para entrar a debatir la problemática planteada y para sustentar la hipótesis de la presente investigación académica, que se precisa así: la ausencia de actividad probatoria para la acreditación del delito fuente del tipo penal de lavado de activos es violatoria de garantías fundamentales del sistema penal acusatorio.

\section{CONCEPTO DEL TIPO PENAL DE LAVADO DE ACTIVOS}

La expresión lavado de dinero (money laundering) proviene de la jerga del hampa -de la mafia europea en los Estados Unidos, liderada por Al Capone- y se origina en la utilización de empresas fachada-lavanderías- para legalizar recursos provenientes de actividades delictivas. En distintos países se utilizan expresiones, igualmente coloquiales, en términos parecidos, como: blanqueo de capital, lavado de capital, lavado de activos, blanqueo de bienes, entre otras (Arangue Sánchez, 2000, p. 23).

Tales términos no reflejan un concepto jurídico, científico. Por ello, algunos autores, inconformes con la simplicidad del vocablo, han propuesto alternativas más ajustadas a derecho: legalización, conversión, naturalización, etc. (Álvarez Pastor y Eguidazu Palacios, 2007, p. 40).

Sin embargo, son múltiples los conceptos diseñados tanto por la doctrina como por la jurisprudencia relevante, y es pertinente mencionar que todos coinciden en una finalidad superior, que consiste en la legalización de los recursos ilícitos provenientes de cualquier actividad delictiva. Para efectos de la presente investigación, se reseña la opinión de algunos académicos que desde distintas ópticas profesionales han enriquecido el desarrollo conceptual del tipo penal objeto de estudio.

El autor español Rafael Gálvez Bravo (2014) ha señalado que el lavado de capitales a través de distintas acciones busca incorporar al sistema comercial, las utilidades generadas por la conducta criminal, simulando una apariencia legal para su debido uso (p. 18).

Según el profesor holandés John Vervaele (2011) el lavado de activos es una serie de fases progresivas, cuyo objeto es integrar las ganancias ilícitas al sistema económico legal, ocultando su ilicitud (p. 32).

En la misma línea argumentativa, Juana del Carpio Delgado (1997) precisa que la esencia del tipo penal no es la configuración de alguno de los verbos rectores, sino el desarrollo de cualquier acción para disimular el origen criminal de los bienes ilícitos (p. 166). 
A su vez, el tratadista André Luís Callegari (2009) deja sentado que el lavado es cualquier procedimiento para integrar las utilidades ilícitas al sector financiero con apariencia legal (p. 59).

En esta misma dirección, el autor peruano Hinostroza Pariachi (2009) identifica el blanqueo de capitales como aquellas acciones para simular la naturaleza criminal de bienes, ingresándolos en sector económico (p. 37).

La Unidad de Información y Análisis Financiero (UIAF), unidad de inteligencia financiera y económica de Colombia, cuya misión se centra en la defensa y seguridad nacional en el ámbito económico, ha establecido que el lavado de activos es el procedimiento en virtud del cual las empresas criminales simulan legalidad a los capitales delictivos, y en ciertos eventos obteniendo utilidades de los mismos (UIAF, 2014, párr. 1).

El profesor colombiano Hernando Hernández Quintero (2011), con su acostumbrada solvencia, establece dos conceptos de lavado de activos, uno amplio y otro restrictivo. En el criteri o amplio el blanqueo de capitales es cualquier acto comercial con miras a introducir al ámbito mercantil capitales de origen ilegal y actos de apariencia simulando legalidad (p. 56). Con relación al criterio restringido propuesto por el citado maestro, es el método por medio del cual se introduce al sector bancario patrimonios derivados de acciones ilegales y demás procedimientos inclinados a apartar el capital de su fuente, evitando su rastreo, con el objeto de incorporarlos a la economía, simulando su naturaleza legal.

Como puede observarse, la literatura universal trae consigo distintos conceptos sobre lo que se entiende por lavado de activos, lavado de dinero y blanqueamiento de capitales, pero absolutamente todos están unidos con el fin de ocultar aquellos recursos ilícitos y su posterior inserción en el sistema económico de un determinado territorio (Hernández Quintero, 2013, p. 484).

Es necesario mencionar que el fundamento más importante para la utilización de herramientas legales orientadas a la prevención y criminalización del tipo penal estudiado, en el desarrollo del compromiso adquirido en tratados internacionales de combatir el narcotráfico (Sintura, Martínez y Quintana, 2011, p. 13; Hernández Quintero, 2013,p. 492), sus utilidades ilícitas y cualquier comportamiento con el fin de dar un semblante de legalidad.

Por último, vale la pena indicar que el delito de lavado de activos se deriva de la comisión de un ilícito penal -delito fuente-, el cual genera ganancias ilícitas. Por ende, una de las principales características del tipo penal de lavado de activos es su conexión con el delito fuente, puesto que la materialización de la conducta de lavado de activos depende de si la ganancia, utilidad, bien o dinero procede de acciones delictivas, y se busca su legalización. Por tanto, el delito fuente es toda conducta 
delictiva que genera activos ilícitos que son objeto de conversión en capitales lícitos (Hinostroza Pariachi, 2009, p. 32).

\section{GRADO DE UNIÓN ENTRE EL DELITO FUENTE Y EL DELITO DE LAVADO DE ACTIVOS}

Con miras a evidenciar los nexos entre estos dos tipos penales, nada mejor que iniciar con las distintas elaboraciones por parte de la doctrina, cuando plantea que el tipo penal de lavado de activos requiere como presupuesto la comisión de un hecho delictivo previo, cuyo objeto material deriva ganancias ilegales, sobre las que va a recaer la conducta típica de lavado de activo (Carpio Delgado, 1997, p. 117; Hinostroza Pariachi, 2009, p. 139 y Callegari, 2009, p. 123). De no materializarse dicho nexo, no podría existir objeto material apto para la comisión del tipo penal de lavado de activos (Carpio Delgado, p. 123).

En un principio, la mayoría de las legislaciones foráneas entendían el delito fuente como cualquier actividad que se encuadrara en el precepto legal del tráfico de drogas. Sin embargo, dicha concepción fue abandonada en virtud de la nueva realidad observada en el mundo delictivo, cuando enseña que la comisión de distintos delitos pueden generar igual o mejores ganancias de las que provee el mundo del narcotráfico o del terrorismo, generando capitales ilícitos capaces de desestabilizar la economía de un país (Callegari, 2009, p. 123).

Así, cada país ha adoptado distintos sistemas para la delimitación sobre qué se debe entender por delito fuente. Los distintos sistemas pueden ser de tres clases: amplio, intermedio o restringido. El amplio hace referencia a que el delito previo puede ser cualquier tipo doloso; el intermedio reseña la gravedad de algunos delitos establecidos por el legislador, y el restringido son todos aquellos delitos fuentes que están expresamente previstos en la ley (Callegari, 2009, 123. En el mismo sentido: Carpio Delgado, 1997, p. 120). Colombia adopta un sistema de numerus clausus, sobre el cual se advierte que continuamente se está ampliando el número de delitos previos consagrados en el artículo 323 del Código Penal colombiano. El profesor Miguel Bajo Fernández (2009) critica este proceder al afirmar que las modificaciones del delito fuente obedecen a un "derecho penal expansivo impropio de un Estado liberal" (p. 12) promovido por organizaciones internacionales con el pretexto de la nueva lucha contra la criminalidad organizada supranacional (p. 11).

Otras de las relaciones entre el delito fuente y el delito de lavado de activos es la relativa a la autonomía de este último, por tal razón, se han desarrollado dos tesis opuestas. De una parte, se concibe el delito de lavado de activos como accesorio al delito fuente - protegiendo el mismo bien jurídico-y, por otro lado, se entiende el tipo penal de lavado de activos como una figura legal autónoma con objeto jurídico de protección distinto (Hinostroza Pariachi, 2009, p. 140). La doctrina mayoritaria 
se inclina por esta última postura y, en ese orden de ideas -y en virtud de ser considerado como una figura autónoma con bien jurídico independiente-, el delito de lavado de activos se fundamentaría en la incorporación de capitales ilícitos en el torrente legal económico (p. 141).

Para el caso colombiano, el constituyente secundario, consciente de los efectos negativos que traía consigo la inclusión del delito de lavado de activos como una de las formas de receptación -como lo había concebido la Ley 190 de 1995-, aprobó la ley 365 de 1997, que estableció el lavado de activos como un tipo penal autónomo y lo ubicó en el título x del Código Penal colombiano, como un comportamiento que lesiona el orden económico y social.

Así las cosas, concebir el delito de lavado de activos como delito autónomo trae consigo otro nexo entre este y el delito fuente, el cual se expresa a través del principio de accesoriedad limitada, que resuelve las dificultades de participación en un delito cometido por su autor o persona distinta del partícipe (Carpio Delgado, 1997, p. 125), al establecer que la responsabilidad del partícipe, está condicionada por la acción cometida por el autor, la cual debe ser típica y antijurídica (Muñoz Conde, 2007, p. 437). Por consiguiente, con base en la línea dogmática trazada por la doctrina universal al considerar que delito es toda acción u omisión típica, antijurídica, culpable y punible -accesoriedad máxima-, frente al delito fuente - del cual se derivan los capitales ilícitos objeto material del delito de lavado de activos-, bastará que la conducta sea típica y antijurídica para entender la consumación de este último, sin que sea necesaria la constatación de la culpabilidad del sujeto activo (Hinostroza Pariachi, 2009, p. 128).

De ahí que la literatura jurídica indique dos teorías en materia procesal para la constatación de la comisión de delito fuente: 1) acreditación del delito fuente por medio de un proceso judicial en donde los distintos elementos de prueba indiquen la responsabilidad penal del autor o participe, la cual es reflejada en una sentencia condenatoria en firme -para así proseguir con el proceso penal de lavado de activos- y 2) basta la verificación por medio de indicios razonables -por parte del juez que conoce el proceso de lavado de activos-, sobre la realización del hecho típico y antijurídico del delito fuente sin necesidad que exista sentencia condenatoria en firme sobre este último (Hinostroza Pariachi, 2009, pp. 142 y ss.).

En tal sentido, las legislaciones foráneas han adoptado la segunda tesis y, en virtud de ello, en materia procesal se denota la autonomía del delito de lavado de activos frente al delito fuente, porque no es necesario sentencia condenatoria por el delito base, sino que se permite la constatación del origen de los activos ilícitos -delito fuente-, por medio de la prueba indiciaria en el mismo proceso adelantado por lavado de activos (p. 145).

Otra relación entre el delito fuente y el delito de lavado de activos es la relativa a la independencia de este último, por cuanto la pena no está subordinada por la pena del 
delito fuente. En ese orden de ideas, la pena del delito de lavado de activos puede ser mayor que la pena prevista para el delito fuente (p. 145).

En la legislación penal colombiana, el grado de unión entre los dos tipos penales analizados es la incorporación del delito fuente en la redacción del artículo 323 -lavado de activos- del Código Penal colombiano, en donde se aprecia que el constituyente secundario optó por una medida radical y enormemente desfavorable desde un punto de vista político-criminal, abogando por un expansionismo del derecho penal en aras de contrarrestar la nueva criminalidad organizada. Por esta razón, el legislador ha ampliado el catálogo de los delitos base que originan capitales ilícitos, como puede observarse en las últimas reformas, en las cuales se advierte también el aumento constante de la pena para el punible de lavado de activos y el incremento de verbos rectores. -Véanse: artículo 17 de la Ley 1121 de 2006, artículo 42 de la Ley 1453 de 2011, artículo 11 de la Ley 1762 de 2015-.

\section{LA PRUEBA DEL DELITO FUENTE EN EL SISTEMA PENAL COLOMBIANO}

La garantía procesal del principio de inocencia demanda que se demuestre la responsabilidad penal del agente en un debido proceso (Montero Aroca, 1997, p. 152). En consecuencia, en el ámbito de lavado de activos se requiere acreditar la actividad ilícita generadora de capitales ilícitos -delito fuente-. Recapitulando líneas precedentes, existen dos posibilidades para su constatación: acreditar la comisión del delito fuente por medio de sentencia condenatoria, como consecuencia del desarrollo de un debido proceso independiente del de lavado de activos, o que el juez o tribunal que conoce del delito de lavado de activos determine por medio de la prueba indiciaria la comisión de dicho delito (Hinostroza Pariachi, 2009, pp. 146), sin necesidad de un debido proceso, actividad probatoria, sentencia condenatoria. Tendencia seguida por parte de la doctrina y la jurisprudencia contemporáneas.

Para ampliar el tema del presente artículo, uno de los problemas que germinan frente a la prueba del delito fuente es que el legislador colombiano no estableció el requisito procesal de la condena previa del delito fuente para la sanción por el delito de lavado de activos, concediendo tal honor a la actividad jurisprudencial por parte de la Corte Suprema de Justicia -Sala Penal-, vía que ha sido homogénea dado que su misma línea ha consolidado una tesis extrema y controversial; verbigracia, el delito subyacente se debe probar a partir de una inferencia judicial, sin necesidad de una actividad probatoria, el delito fuente no se demuestra por medio de la prueba acreditada en proceso penal independiente al de lavado de activos y se refleja en sentencia condenatoria.

La discusión se centra, precisamente, en el medio de prueba que se exige para acreditar la actividad generadora de capitales ilícitos que posteriormente son objeto de 
blanqueo, en cuál de las dos - prueba indiciaria o prueba directa- sustenta de forma clara y contundente el ilícito previo. Y sobre todo, en si la ausencia de actividad probatoria para la acreditación del delito fuente transgrede principios constitucionales y procesales con incidencia en el proceso penal acusatorio.

En el año 2005, mediante sentencia de 19 de enero (Proceso 21044), la Corte Suprema de Justicia -Sala Penal- varió ostensiblemente su posición, al establecer la tesis de que la investigación, procesamiento y condena del delito matriz no son requisitos para sancionar el ilícito de lavado de activos. Asimismo, en sentencia del 9 de marzo de 2006 (Proceso 22179) dio inicio a la línea jurisprudencial sobre la prueba del delito subyacente, centrándose en el estándar probatorio para acreditar el supuesto jurídico, es decir, el indicio.

Luego, en sentencias del 24 de enero de 2007 (Proceso 25219) y del 9 de abril de 2008 (Proceso 23754), la Corte agregó como elemento indicativo para la acreditación del delito fuente el comportamiento del acusado.

Finalmente, la Sala de Casación Penal reafirmó en las sentencias del 11 de marzo de 2009 (Proceso 26144) y del 2 de febrero de 2011 (Proceso 27144) la tesis de que el delito subyacente debe ser meramente sugerido por medio de la inferencia lógica, sin necesidad de ser comprobado a través de un procedimiento penal, descartando cualquier grado de conocimiento de certeza que acredite el delito subyacente.

Así pues, por la vía jurisprudencial se ha superado el vacío legal referente al estándar probatorio para la acreditación del delito matriz, estableciendo para dicho fin, el indicio, el comportamiento del acusado, la inferencia judicial y lógica, como los elementos de juicio más idóneos. Sin dejar a un lado que la acreditación del delito fuente no está condicionada a una actividad probatoria que le antecede en el marco de un debido proceso penal, culminando con un pronunciamiento judicial.

La postura de la Sala de Casación Penal de la Corte Suprema de Justicia resulta criticable, en la medida en que desconoce argumentos conceptuales que sustentan figuras de carácter sociojurídico, verbigracia: la verdad material, verdad procesal, la verdad de los hechos, ¿cuál es el mecanismo más idóneo para su acreditación?, la finalidad del proceso y el debido proceso penal, así como la importancia de la actividad probatoria para el convencimiento judicial. Además, es curioso que el mismo órgano de cierre de la justicia ordinaria desconozca su propia jurisprudencia centenaria sobre el debido proceso, la prueba y la actividad probatoria -como mecanismo idóneo para respaldar la decisión judicial y la demostración de un ilícito penal-, las consecuencias jurídicas que trae consigo emitir juicio de responsabilidad penal sin fundamento en un acervo probatorio y, sobre todo, el menosprecio de los principios rectores del método acusatorio para sustentar condena penal. Es verdad que el anterior salto legal se deriva de la desafortunada redacción de los artículos que regulan todo lo relacionado con el tipo penal del lavado de activos -teniendo en 
cuenta que el legislador no estableció la no punición del delito previo para condenar por lavado de activos- $y$, ciertamente, la postura jurisprudencial es debida al ánimo de cumplir cabalmente los preceptos emanados por el Grupo de Acción Financiera Internacional, GAFI (Bajo Fernández, 2009, p. 12) y otros organismos internacionales.

No obstante, vale la pena reseñar que la actual línea jurisprudencial de la Sala Penal de la Corte Suprema colisiona con la vía garantista que la Corte Constitucional ha desarrollado con suficiencia desde una perspectiva constitucional de los fines del proceso penal: búsqueda de la verdad, respeto de principios y reglas probatorias que regulan el debido proceso penal, entre otras garantías (Sentencia C-396, 23 de mayo de 2007).

La postura de la Corte Suprema de Justicia desconoce los fines del proceso penal, que orientan la obtención razonable de la verdad por medio del cumplimiento de las reglas probatorias, actividad probatoria, para la consecución de la convicción judicial (Urbano Martínez, 2012, p. 113). Garantías procesales que nutren nuestro Código Penal y se reflejan en el postulado penal constitucional "conocimiento para condenar" -Para condenar se requiere el conocimiento más allá de toda duda, acerca del delito y de la responsabilidad penal del acusado, fundado en las pruebas debatidas en el juicio. La sentencia condenatoria no podrá fundamentarse exclusivamente en pruebas de referencia (Código de Procedimiento Penal, art. 381)-, el cual está íntimamente ligado a la garantía del derecho de la prueba consagrada en el artículo 29 de la Constitución colombiana: derecho a asegurar la prueba, decreto de pruebas, práctica de las pruebas ya decretadas, controversia de la prueba, valoración de la prueba regularmente aportada al proceso (Parra Quijano, 2008, pp. 116 y ss.).

Sentadas las anteriores bases, es inevitable hacer un contraste entre dos posiciones jurídico-filosóficas que se adecuan en el tópico del conocimiento para condenar en el sistema acusatorio. ¿Cuál de los extremos propuestos, la materialización de la actividad probatoria o la ausencia de esta -en el caso, para la acreditación del delito fuente- es idóneo para la convicción judicial a fin de la consecución de la verdad procesal, con respeto de las garantías constitucionales del proceso penal?

\section{LA MATERIALIZACIÓN DE LA ACTIVIDAD PROBATORIA COMO EL MEDIO MÁS IDÓNEO PARA EL CONVENCIMIENTO JUDICIAL}

El profesor Gómez Colomer (2010) sostiene que el proceso penal es el medio para develar y judicializar la conducta criminal atribuida a una persona (p. 108). En esa misma línea, Bacigalupo (2007) sostiene que el fin de la investigación preliminar en el debido proceso es esclarecer un hecho, la del juicio obtener la convicción (p. 51). Asimismo, según Maier (2012), la aseveración de que una acción u omisión ha vulnerado determinado bien jurídico constituye la génesis del debido proceso penal, 
en la medida en que este establece los actos procesales a necesarios para confirmar la hipótesis delictiva y, en su caso, imponer la sanción jurídica adecuada (p. 86). Así pues, el derecho procesal penal ha diseñado un procedimiento idóneo para develar la verdad y lograr la convicción sobre lo sucedido (p. 86), incluso la literatura procesal argentina afirma que el "Derecho procesal penal es el único medio legítimo para la realización penal" o "Derecho penal material" (p. 85).

De ahí que se afirme que el concepto de verdad y el de proceso penal están íntimamente ligados, en la medida en que el primero busca la consecución de la verdad sobre la imputación criminal, partiendo de una duda o hipótesis por confirmar, buscando incorporar la prueba eficaz para el convencimiento judicial y así conocer la realidad material (Maier, 2012, p. 848).

Por otro lado, el profesor Taruffo (2005) sostiene que el "hecho es el objeto de la prueba y esta última sirve para establecer la verdad de uno o más hechos relevantes para la decisión" (p. 89). Entonces, la prueba -entendida como toda información introducida al proceso penal, que sea apta para producir un juicio certero sobre los límites de la hipótesis delictiva (Vélez Mariconde, 1981, citado en Cafferata Nores y Hairabedián, 2013, p. 19)- servirá para fundar los límites del conocimiento que el fallador puede introducir en el proceso penal a efectos del convencimiento judicial, eliminando la posibilidad de aplicar la ciencia privada sobre los hechos que deben ser acreditados en el proceso penal -con la pretensión de no acreditar el hecho en sí mismo, sino en la medida que este sea el supuesto para la aplicación de normas penales en el tema concreto (Taruffo, 2005, p. 90)- y fundar sobre estos hechos un juicio de probabilidad. El elemento probatorio es, entonces, el único medio legítimo para develar la verdad y constituye el garante esencial contra la arbitrariedad judicial (Caffferata Nores y Hairabedián, 2013, p. 5; Parra Quijano, 2008, pp. 73 y ss.). Y como afirma el destacado profesor Caffferata Nores, el juicio de culpabilidad debe recaer sobre los datos probatorios legítimamente conseguidos y legalmente añadidos al proceso penal. "Son las pruebas, no los jueces las que condenan; esta es la garantía” (Cafferata Nores y Hairabedián, 2013, p. 5).

Ahora bien, teniendo en cuenta lo anterior, el proceso penal y la prueba penal están unidos en grado de un fin común: brindar conocimiento al juez -en grado de certeza- sobre la ocurrencia o no de los supuestos fácticos que sostiene la acusación (Urbano Martínez, 2012, pp. 114 y ss.), y que el medio legalmente admitido para ello es la prueba, resalta la importancia de la actividad probatoria entendida como el esfuerzo de todos los intervinientes procesales, tendiente a la producción, recepción, contradicción, y valoración de los elementos de prueba (Cafferata Nores y Hairabedián, 2013, p. 54). Es entonces la actividad probatoria el engranaje vital del sistema acusatorio, y sirve de medio para que este pueda alcanzar el fin propuesto.

Del mismo modo, la Corte Constitucional ha establecido la noción de actividad probatoria en el entendido de que está compuesta por dos clases de actos: los actos 
de investigación y los actos de prueba. Los primeros hacen referencia a toda acción tendiente a recaudar $\mathrm{u}$ obtener evidencia y elementos materiales probatorios que puedan ser utilizados en juicio oral, con el fin de sustentar las distintas tesis propuestas por los sujetos de derecho. Los segundos son todas aquellas actuaciones que realizan los sujetos procesales ante el juez de conocimiento, con el fin de incorporar los actos de investigación al juicio, convirtiéndolos en pruebas (Sentencia C-144, 3 de marzo de 2010), para así determinar la veracidad o falsedad de los hechos alegados, como soporte de su pretensión (Durán Climent, 2011, pp. 78 y ss; Ignacio Anitua, 2010 , pp. 125 y ss.).

Así mismo, el tribunal garante de la Carta Magna colombiana ha evidenciado la importancia de la actividad probatoria en virtud de su característica adversarial, pues el juez está obligado a decidir con base en las pruebas que los sujetos procesales presentan para su convicción. La pasividad probatoria del juez constituye una garantía del acusado (Sentencia C-144, 3 de marzo de 2010).

Teniendo en cuenta lo anterior, se puede afirmar que la actividad probatoria la constituyen todos aquellos actos al interior del procedimiento que buscan la incorporación y valoración de un elemento de prueba (Florian, 1982, citado por Maier, 2012, pp. 858 y ss.). Es la producción de la prueba -actividad probatoria-el método regulado jurídicamente que efectivamente conduce al conocimiento certero de determinado hecho (Maier, 2012, pp. 858 y ss.).

Por otro lado, en materia criminal, los distintos códigos foráneos establecieron la mayor parte de la actividad probatoria en el órgano acusador y, en diferente intensidad, en el procesado, imputado/acusado, querellante, tercero civilmente responsable, etc. (Maier, 2012, p. 54). Sin embargo, y en virtud del principio de la carga dinámica de la prueba, el papel de la defensa adquiere mayor relevancia en la medida en que no se limitará únicamente a aportar la prueba que tenga en su poder para desvirtuar la acusación - presencia pasiva del procesado penal-, sino que se exige el deber de recaudar por cuenta propia los elementos materiales probatorios para desvirtuar los fundamentos fácticos-jurídicos de la acusación (Urbano Martínez, 2012, pp. 122 y ss.). Por consiguiente, la actividad probatoria en la actual estructura probatoria del proceso involucra a todos los sujetos procesales -juez, partes intervinientes- y establece obligaciones y límites en aras del respeto de los principios y garantías del debido proceso, el juicio oral, eliminando así cualquier conocimiento privado del fallador (pp. 184-185).

Los distintos sistemas procesales penales de carácter acusatorio se estructuran en etapas comunes, cada una de ellas con objetivos concretos que reflejan el desarrollo progresivo de la actividad probatoria con incidencia en la incorporación, producción, percepción, contradicción y valoración del elemento probatorio que sustenta la teoría del caso de los sujetos procesales, legitimando así el convencimiento judicial. 
Es de claro entendimiento que, tal como lo menciona el profesor Jauchen (2012), no solo se debe procurar el cumplimiento de cada una de las etapas procesales, sino que debe atenderse también a la realización consecutiva de la actividad probatoria desplegada al interior de cada una de estas para satisfacer los lineamientos constitucionales con relación a todos los intervinientes procesales (Jauchen, 2012, p. 527). El "Estado de Derecho republicano y democrático debe necesariamente agotarse a fin de comprobar, mediante la producción de pruebas y las argumentaciones pertinentes, la certeza del contenido de la acusación y solo así, quebrar el estado de inocencia, legitimando la aplicación de la sanción penal" (p. 531).

Algunos sectores de la doctrina del Cono Sur, concuerdan en que la actividad probatoria se divide en tres momentos procesales: proposición, recepción, valoración (Cafferata Nores y Hairabedián, 2013, p. 60); o conformación, valoración y decisión (Ferrer Beltrán, 2013, p. 24). Otro sector de la academia jurídica, los define como proposición, admisión, práctica, valoración (Gómez Colomer, 2010, pp. 312 y ss.), e incluso algunos autores continentales no delimitan el procedimiento probatorio -actividad probatoria-, sin embargo, coinciden en distinguir momentos fundamentales en el proceso, regidos por el derecho probatorio con la finalidad del convencimiento judicial ${ }^{1}$. Lo cierto es que -independientemente de los distintos enfoques conceptuales- el desarrollo de la actividad probatoria es un reflejo de un "proceso con todas las garantías" (Bacigalupo, 2007, p. 50) que legitima el procedimiento penal desde el ámbito constitucional e incluye en sí principios inherentes de un sistema acusatorio, verbigracia: publicidad, inmediación, oralidad, contradicción, concentración, acusatorio, presunción de inocencia y otros más, legitimando así el convencimiento y la decisión judicial (p. 50).

La proposición, ofrecimiento o admisión de la actividad probatoria hace referencia a todos los actos procesales efectuados por las partes tendientes a la introducción de un elemento de prueba (Florian, 1982, citado por Maier, 2012, pp. 858 y ss.) con el fin de que el debate probatorio recaiga sobre las pruebas allegadas y admitidas en la fase de juicio oral (Ferrer Beltrán, 2013, p. 25). El medio de prueba deberá cumplir con los requisitos legales exigidos para la admisión de la prueba, de modo que únicamente sean admitidos por el juez los elementos probatorios pertinentes, conducentes, útiles y relevantes, excluyendo aquellas pruebas que hayan sido obtenidas con violación a los derechos fundamentales (Barona Vilar, 2010, pp. 312 y ss.). Este momento procesal es de suma importancia para el juicio oral, en la medida

1 Para estos efectos, pueden consultarse: JAUCHEN (2012, pp. 526 y ss.), DurÁn Climent (2011, pp. 78 y ss.), Morales Rivera (2011,pp. 159 y ss.), Armenta Deu (2004, pp. 260 y ss.), Armenta DEU (2014, pp. 78 y ss.), ANitua (2010,pp. 125 y ss.), Bovino (2006,pp. 235 y ss.), Bacigalupo (2007, pp. 49 y ss.), CAFFERATA Nores (2008, pp. 78 y ss.), TARuffo (2013,pp. 109 y ss.), Montero Aroca (1997, pp. 137 y ss.), Nieva Fenol (2012,pp. 282 y ss.), JAUCHEN (2005, pp. 77 y ss.) y Maier (2012, pp. 858 y ss.). 
en que funciona como filtro jurídico del elemento de prueba que busca su inclusión (Ferrer Beltrán, 2013, p. 25).

Ahora bien, la recepción, práctica o asunción es el momento del ingreso efectivo del elemento probatorio en la fase de juicio oral (Florian, 1982, citado por Maier, 2012, pp. 858 y ss.). La práctica de la prueba debe cumplir cabalmente con los principios de raigambre constitucional que regulan el sistema penal acusatorio -inmediación, contradicción, concentración, oralidad, publicidad, etc.-, garantías que presiden la producción de la prueba durante el debate en la fase de enjuiciamiento acusatorio adversarial (Barona Vilar, 2010, pp. 312 y ss.). Es pertinente anotar que la práctica de la prueba en el marco contradictorio debe ser sometida a las reglas propias, siguiendo así las distintas variables procesales que influyan en ella. De la misma forma, se deberá seguir el orden legal establecido para su producción y refutación (Armenta Deu, 2004, pp. 263 y ss.). El derecho de producir pruebas de cargos y de descargos, la facultad de argumentar su eficacia probatoria para la acreditación de los elementos de la situación fáctica que sustenta la acusación son caracteres sustanciales de la fase de recepción (Cafferata Nores, 2008, p. 171 y ss.). Así mismo, conviene destacar que actualmente hay consenso universal en cuanto a que los actos probatorios producidos en juicio - práctica de pruebas- ante la presencia de todos los sujetos procesales, representan una garantía sobre la "monstruosa idea de que al imputado se lo condena en virtud de pruebas recibidas a sus espaldas y antes del verdadero juicio" (Vélez Mariconde, 1981, citado por Bovino, 2006, p. 260).

Finalmente, el tercer momento de la actividad probatoria es la valoración de los elementos de prueba, entendida como aquel ejercicio intelectual-argumentativo destinado a establecer la eficacia convencional de los elementos de pruebas practicados en fase de juicio oral. La operación consiste en adoptar un estándar de valoración sobre la prueba para así establecer el grado de conocimiento y la probabilidad de certeza sobre los límites de la acusación (Schiavo, 2013.p. 52 y ss.; Ferrer Beltrán, 2013, p. 25; Cafferata Nores y Hairabedián, 2013,p. 64). O, en palabras sencillas del profesor Cafferata Nores: "qué prueba la prueba". (Cafferata Nores y Hairabedián, 2013, p. 64). Por cierto, durante el debate de juicio oral, todos los sujetos procesales podrán valorar la prueba, con el fin de evidenciar su credibilidad en aras de inducir la ocurrencia en grado de certeza en relación a un hecho específico. El objeto es, entonces, establecer la veracidad de la prueba o, por el contrario, su falsedad (Taruffo, 2013, pp. 139 y ss.). Sin embargo, el juez, en últimas, deberá adoptar cualquiera de los sistemas legitimados para la valoración de la prueba, sustentando el proceso racional que condujo para la afirmación de su hipótesis y representando así el convencimiento judicial, que elimina cualquier tipo de duda frente a la decisión judicial (Morales Rivera, 2011, pp. 304 y ss.).

En síntesis, el proceso penal está encaminado hacia la búsqueda de la verdad que versa sobre un objeto en particular, constituido por hechos realizados por la conducta 
humana, que supuestamente se encuadra en un tipo penal. Dicho sistema procesal -indagación, investigación y juicio- se desenvuelve en el marco de un conjunto de principios, garantías y reglas - de carácter sustancial y procedimental- que limitan el desarrollo de la actividad probatoria, buscando así que del acervo probatorio se desprenda un cierto grado de probabilidad que sustente el convencimiento judicial sobre los presupuestos fácticos que sostienen determinada hipótesis judicial (Morales Rivera, 2011, p. 304)

La responsabilidad penal que descansa sobre los presupuestos dogmáticos de los elementos del tipo penal será legitimada en la medida en que la acción, la tipicidad, la antijuridicidad y la culpabilidad sean objeto de un juicio penal en el que resulten aseguradas al máximo la proposición, producción, contradicción, valoración, etc. de la actividad probatoria. El juicio penal resulta ser un conjunto de garantías procesales penales que, valorado como un todo, refleja la máxima garantía procesal, presupuesto de todas las demás; esto es, el principio de jurisdiccionalidad que, en palabras del profesor Ferrajoli (2009), garantiza "el descubrimiento de una verdad sustancial y global fundada esencialmente sobre valoraciones, asegurando la prevención de las venganzas y de las penas privadas" (p.538). Vale la pena mencionar que el principio de jurisdiccionalidad está implícito en el artículo 29 de nuestra Carta Magna.

En consecuencia, el principio de jurisdiccionalidad en el proceso penal condiciona la sanción del delito, la acreditación de un hecho delictivo, al desarrollo del juicio penal con observancia de una efectiva actividad probatoria. Se afianza así la garantía de presunción de inocencia, en virtud de la cual nadie puede ser declarado judicialmente culpable sin un juicio legal previo - con observancia de los principios de la actividad probatoria- ni, mucho menos, antes de que este concluya (Ferrajoli, 2009, p. 538).

El principio de jurisdiccionalidad, que establece la obligación de un debido proceso, es la vía necesaria para la obtención del elemento probatorio que acredita la comisión de un delito. Hasta que la prueba condenatoria no se conforme por medio de la actividad probatoria bajo la regulación de un juicio, absolutamente nadie podrá ser considerado penalmente responsable ni, mucho menos, se deberá dar por sentada la acreditación de un hecho ilícito. En ese sentido, si la hipótesis delictiva -acusaciónno es sometida a la actividad probatoria que conforma la prueba bajo la observancia de las reglas del juicio, se entenderá que esta jamás se materializó: "nullum iudicium sine accusatione, sine probatione y sine defensione” (Ferrajoli, 2009, p. 539).

Resulta, pues, que la actividad probatoria al interior del juicio penal es el medio más idóneo para acreditar la verdad o falsedad de los hechos alegados por alguno de los sujetos procesales, es el esfuerzo probatorio de todos los que conforman la prueba puesto que brinda los elementos de juicio necesarios para el convencimiento judicial de la ocurrencia de determinado hecho. 


\section{LA AUSENCIA DE ACTIVIDAD PROBATORIA PARA LA ACREDITACIÓN DEL DELITO FUENTE DEL TIPO PENAL DE LAVADO DE ACTIVOS VULNERA GARANTÍAS FUNDAMENTALES DEL DEBIDO PROCESO PENAL}

Las constituciones democráticas han incorporado un modelo de constitucionalización del proceso penal, es así como en el procedimiento penal se habla de garantismo para referirse a aquellos mecanismos procesales para tutelar los derechos fundamentales, exigibles y de aplicación inmediata en cualquier tipo de proceso, que operan como garantía para la obtención de la verdad procesal sobre los elementos fácticos debatidos en juicio (Morales Rivera, 2011, pp. 385 y ss.; Ferrajoli, 2009, pp. 540 y ss.).

La doctrina especializada ha reconocido que el debido proceso es un conjunto de derechos y principios procesales que están presentes en cada etapa del proceso e igualmente en las distintas fases que conforman la actividad probatoria: solicitud, proposición, admisión, recepción, práctica, valoración de la prueba y decisión. Ello implica que los sujetos procesales pueden desplegar todos sus derechos procesales, con el fin de que se cumplan los requerimientos legales para la práctica probatoria, con miras a la obtención de una decisión judicial fundada sobre valoraciones (Morales Rivera, 2011, p. 304).

Asimismo, el debido proceso concede la facultad de ejercer los principios constitucionales rectores del método acusatorio: oralidad, contradicción, publicidad, concentración, inmediación, presunción de inocencia, in dubio pro reo, igualdad, publicidad, legalidad y derecho a presentar pruebas; este último, vértebra sustancial del debido proceso. Es más, el debido proceso lleva implícito el ejercicio de la actividad probatoria, proceso de gran importancia para la causa penal, pues la pretensión, tanto del procesado como del ente acusador, será correspondida como consecuencia de su despliegue en todo su esplendor.

Ahora bien, es conveniente destacar que el derecho procesal penal incorpora una serie de reglas que regularizan la sentencia final y el procedimiento para su obtención -actividad probatoria-, que contienen los elementos de juicio que únicamente serán válidos para la adopción de la decisión, dotando a esta de autoridad acerca de los hechos probados como consecuencia del ejercicio de los tres momentos de la actividad probatoria (Ferrer Beltrán, 2007, pp. 35, 40).

Ya en este punto, cabe afirmar que el procedimiento penal, el debido proceso y la actividad probatoria son elementos fundamentales para la obtención de una decisión democrática ajustada a derecho.

Cualquier decisión judicial que acredite como cierta la ocurrencia de un hecho criminal -tipo penal- sin el ejercicio idóneo de la actividad probatoria, de los principios rectores y garantías fundamentales del sistema penal acusatorio constituye una clara 
violación al debido proceso y se considerará una decisión ilegítima, carente de la observancia de preceptos superiores y, a su vez, representativa de una punición arbitraria (Ferrajoli, 2009, pp. 543 y ss.). La inviolabilidad del principio general de la defensa en juicio -y demás derechos conexos- es característica de cualquier método acusatorio legítimo y democrático (Carrió, 2010, p. 117).

A partir de estos presupuestos, se puede afirmar que la acreditación del delito fuente del delito de lavado de activos por medio de una inferencia judicial fundada en prueba indiciaria, sin la observancia de una actividad probatoria por parte de los sujetos procesales, es violatoria de los principios modulares del debido proceso y del conjunto de garantías que otorga el ordenamiento jurídico a las partes, e infringe además la estructura fundamental del procedimiento y bases fundamentales del debido proceso (Bernal Cuéllar y Montealegre Lynnet, 2013b, pp. 968 y ss.).

Así las cosas, la acreditación del delito fuente del delito de lavado de activos sin el pleno ejercicio de la actividad probatoria viola los principios de imparcialidad, puesto que se configura una intervención del juzgador al dar acreditado el delito previo con ausencia de práctica de pruebas por las partes; legalidad procesal, porque no se observan las formas propias de cada juicio (Solórzano, 2013, pp. 83 y ss.); presunción de inocencia, al existir fracaso probatorio se debe conservar el estatus de inocencia; in dubio pro reo, al no concurrir actividad probatoria la culpabilidad no está acreditada en términos de certeza (Ibáñez, 2009, pp. 83 y ss.); defensa, por la ausencia de facultad de defensa técnica para confrontar la prueba de descargo, juicio justo con todas las ritualidades de ley en término de igualdad (Granados Peña y Morris Liévano, 2015a, pp. 458 y ss.); inmediación, porque no hay una relación directa entre el juez y la práctica probatoria por ausencia de esta última; contradicción, en razón a que el aporte probatorio al juicio no fue objeto de refutación permitiendo su formación (Granados Peña y Morris Liévano, 2015b, pp. 818 y ss.); concentraciónceleridad y eficiencia, pues la inexistencia de actividad probatoria imposibilita su discusión de forma ágil y concentrada en juicio oral (Solórzano, 2013,pp. 128 y ss.; Bernal Cuéllar y Montealegre Lynnet, 2013a, pp. 324 y ss.), y publicidad, porque no se desarrolla un debate público para refutar la prueba indiciaria.

Además, la inferencia judicial fundada en prueba indiciaria -sin el ejercicio de actividad probatoria- que acredita la configuración del delito fuente del delito de lavado de activos transgrede notablemente el marco constitucional del derecho fundamental al debido proceso incorporado en el inciso 1 del artículo 29 de la Carta Magna.

En conclusión, la acreditación del delito fuente para la configuración del tipo penal de lavado de activos necesariamente debe interpretarse de forma concordante con el derecho fundamental al debido proceso, incluido en el artículo 29 de la Constitución Política, en lo que se refiere a la etapa de juzgamiento, defensa técnica, inmediación, derecho a la prueba, actividad probatoria, controversia probatoria y demás garantías fundantes del sistema acusatorio, para así materializar un juzgamiento con todas las garantías. 
Asimismo, el derecho fundamental al debido proceso reconoce una ramificación de principios y garantías de titularidad de los sujetos procesales, al indicar que en sede de juicio oral alcanzan mayor eficacia los fundamentos rectores del sistema acusatorio penal, e igualmente al resaltar que es el momento legítimo para el despliegue de la actividad probatoria, construcción pública probatoria, para la definición de responsabilidad penal (Guerrero Peralta, 2011, pp. 313-314). No se debe olvidar que el marco constitucional del sistema penal acusatorio colombiano fue diseñado como un método de carácter adversarial, en el cual se asigna un rol específico a los intervinientes en relación con el objeto del proceso penal y se consolida un valor de legitimidad de la actividad probatoria para el convencimiento o estándar exigible de la decisión judicial (Guerrero Peralta, 2011. p. 314).

La actividad probatoria en el proceso penal es condición de legitimidad y opera como garantía suprema del convencimiento judicial. Sin ella, la decisión judicial sería sinónimo de arbitrariedad y se violarían todos los principios rectores fundantes del proceso penal. Sin ella, la inferencia judicial -basada en la prueba indiciaria no refutada- que debe hacer el juez para la acreditación del delito fuente del tipo penal de lavado de activos sería más bien una presunción judicial carente de cualquier tipo de certeza, con trasgresión del debido proceso penal.

\section{CONCLUSIONES}

Después de haber analizado la problemática en general, solo resta hacer las siguientes precisiones, con el ánimo de cerrar la posición académica adelantada y sustentada en el presente texto:

El lavado de activos es toda acción encaminada a la conversión de capitales ilícitos en lícitos. Asimismo, las ganancias ilícitas objeto de blanqueo se derivan del desarrollo de actividades ilegales previas: delito previo, subyacente o fuente.

El delito de lavado de activos está debidamente relacionado con el delito previo. La relación simbiótica entre ambos tipos penales está condicionada al origen de capitales ilícitos; sin embargo, estos contienen características únicas que inciden en el ámbito jurídico: autonomía, distinto objeto de protección, penas independientes, accesoriedad limitada del ilícito previo.

En virtud del neopunitivismo penal -derecho penal expansionista-, que invoca razones de política criminal (Pastor, 2012, p. 37), la comunidad internacional ha desarrollado la tesis según la cual para la punición del delito de lavado de activos, al ser considerado un tipo penal autónomo, prácticamente no es necesaria la condena del delito fuente que ocasiona las ganancias ilícitas. Es más, del delito fuente no debe reflejarse en sentencia condenatoria como consecuencia del desarrollo de un proceso independiente, paralelo o previo, del proceso penal de lavado de activos. La 
literatura especializada, la normatividad y la jurisprudencia nacional e internacional concuerdan con tal planteamiento, en el sentido de que para la acreditación del delito fuente bastará una inferencia lógica fundada en prueba indiciaria no refutada de que los recursos ilícitos provienen de un delito, sin necesidad de identificar los presuntos autores materiales, la constatación de las categorías dogmáticas del tipo penal y las circunstancias de tiempo, modo y lugar (García López, 2008).

Por vía jurisprudencial se ha superado el vacío legal referente al estándar probatorio para la acreditación del delito subyacente, estableciendo para dicho fin el indicio, el comportamiento del acusado, y la inferencia judicial y lógica como los elementos de juicio más idóneos, desconociendo que la acreditación del delito fuente no está condicionada a una actividad probatoria que le antecede en el marco de un debido proceso penal, culminando con un pronunciamiento judicial.

Igualmente, la ausencia del dinamismo probatorio para la acreditación o refutación del ilícito fuente constituye una clara excepción al derecho de la prueba y al principio de contradicción. Dicha particularidad legal es avalada y desarrollada por la jurisprudencia colombiana.

El proceso probatorio pretende ofrecer el medio de prueba idóneo para la estructuración del juicio jurídico que incide en la determinación judicial. Por tanto, la actividad procesal probatoria es, por excelencia, el mecanismo para trasmitir conocimiento potencial sobre la comprobación de los hechos como objeto sustancial del procedimiento penal (Döhring, 2007, p. 21).

El derecho fundamental al debido proceso resguarda las facultades del procesado para participar en el proceso penal y sirve como medio para la protección de los fundamentos constitucionales del sistema penal acusatorio. Asimismo, el derecho de la defensa se comprende como uno de las pilares más importantes del debido proceso, en el cual se concreta la garantía de intervención de los sujetos procesales en la formación de la prueba -actividad probatoria-, garantizando así la posibilidad de solicitud, inmediación, práctica, conformación y valoración del elemento de prueba que introduce el dato probatorio para la determinación judicial. Su importancia radica entonces en la facultad de controvertir tanto las pruebas como las acusaciones (Bernal Pulido, 2005, pp. 337, 338).

De ahí que la determinación judicial debe demostrar que la decisión judicial es conforme a derecho (Hernández Marín, 2008, 145). Para ello, es fundamental que se haya obtenido con el pleno respeto de las garantías y principios fundamentales del debido proceso del sistema penal acusatorio, que haya sido consecuencia lógica del ejercicio pleno de la actividad probatoria como medio idóneo para el convencimiento judicial. El cimiento de la sentencia debe ser consecuencia de los actos probatorios practicados en fase de juicio oral (Bovino, 2006, p. 260). 
La acreditación del delito fuente que origina los recursos ilícitos objeto de lavado de activos al interior del proceso de lavado de activos por medio de inferencia judicial compuesta por prueba indiciaria no refutada, sin el ejercicio pleno del derecho de defensa y en ausencia de actividad probatoria -la cual es indispensable para la formación de la prueba- transgrede garantías y principios que rigen la prueba penal.

Igualmente, la inobservancia del dinamismo probatorio en sede de juicio oral transgrede los principios modulares y garantías substanciales del proceso, y quebrantan además la estructura fundamental del procedimiento y las bases fundamentales del debido proceso (Bernal Cuéllar y Montealegre Lynnet, 2013b, p. 968 y ss.).

Por ello, el criterio de la presente investigación es que si bien no se requiere condena previa por el ilícito generador de los recursos objeto de lavado de activos -delito previo-, es fundamental que este se acredite por medio de la actividad probatoria, constatando que los recursos delictivos provienen de alguno de los comportamientos descritos como delito base consagrados en el tipo penal de lavado de activos (Callegari, 2009, p. 287; Hernández Quintero, 2008, p. 158).

Se cree que el anterior planteamiento es respetuoso y garante de los principios modulares del sistema penal acusatorio y así mismo, debe ser la senda jurisprudencial a seguir por parte de la Corte Suprema de Justicia -Sala Penal- de Colombia.

\section{BIBLIOGRAFÍA}

Álvarez Pastor, D. y Eguidazu Palacios, F. (2007). Manual de prevención del blanqueo de capitales. Madrid: Marcial Pons.

AnituA, G. I. (2010). Ensayos sobre enjuiciamiento penal. Buenos Aires: Editores del Puerto.

Arangue SÁnchez, C. (2000). El delito de blanqueo de capitales. Madrid: Marcial Pons.

Armenta Deu, T. (2004). Lecciones de derecho procesal, 2. a ed. Madrid: Marcial Pons.

ARMEnTA Deu, T. (2014). Estudios sobre el proceso penal acusatorio. Bogotá: Temis.

Bacigalupo, E. (2007). El debido proceso penal. Buenos Aires: Hammurabi.

BAJO FERnÁNDEZ, M. (2009). "El desatinado delito de blanqueo de capitales”, en M. Bajo Fernández y S. Bacigalupo (eds.). Política criminal y blanqueo de capitales. Madrid: Marcial Pons. 
Barona Vilar, S. (2010). "El juicio oral”, en J. L. Gómez Colomer, J. Moreno Aroca, A. Montón Redondo y S. Barona Vilar. Derecho jurisdiccional III. Proceso penal, $18 .^{\mathrm{a}}$ ed. Valencia: Tirant lo Blanch.

Bernal Cuéllar, J. y Montealegre Lynnet, E. (2013a). El proceso penal: Estructura y garantías procesales. Tomo I, $6{ }^{\mathrm{a}}$ ed. Bogotá: Universidad Externado de Colombia.

Bernal Cuéllar, J. y Montealegre Lynnet, E. (2013b). El proceso penal: Es-

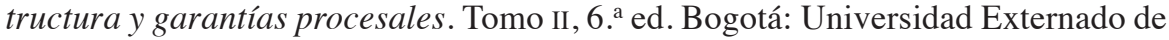
Colombia, 2013.

Bernal Pulido, C. (2005). El derecho de los derechos. Bogotá: Universidad Externado de Colombia.

Blanco Cordero, I. (1997). El delito de blanqueo de capitales. Pamplona: Arazandi.

Bovino, A. (2006). Problemas del derecho procesal penal contemporáneo: Reforma de la justicia pena, imparcialidad, víctima, encarcelamiento preventivo, derecho comparado, juicio oral. Buenos Aires: Editores del Puerto.

Cafferata Nores, J. I. (2008). Proceso penal y derechos humanos: La influencia normativa supranacional sobre derechos humanos de nivel constitucional en el proceso penal argentino, 2. ${ }^{\mathrm{a}}$ ed. Buenos Aires: Editores del Puerto, Centro de Estudios Legales y Sociales.

CAfFerata Nores, J. I. y Hairabedián, M. (2013). La prueba en el proceso penal. Con especial referencia a los códigos procesales penales de la Nación y de la Provincia de Córdoba, 8. ${ }^{\mathrm{a}}$ ed. Buenos Aires: Abeledo Perrot.

Callegari, L. A. (2009). Lavado de activos. Lima: Aras Editores.

Carpio Delgado, J. (1997). El delito de blanqueo de bienes en el nuevo Código Penal. Valencia: Tirant lo Blanch.

CARrió, A. (2010). Garantías constitucionales en el proceso penal, 5. a ed. Buenos Aires: Hammurabi.

Código de Procedimiento Penal (Ley 906 del 2004). Diario Oficial 45658. Colombia: Congreso de la República, 1. ${ }^{\circ}$ de septiembre de 2004.

Código Penal (Ley 599 de 2000). Diario Oficial 44097. Congreso de Colombia, 24 de julio de 2000. 
Conferencia Ministerial Concerniente al Lavado de Dinero e Instrumentos Del Delito (1995, 2 de diciembre). Comunicado Ministerial. Buenos Aires: Cumbre de las Américas. Recuperado del sitio web oficial de la Comisión Interamericana para el Control del Abuso de Drogas, CICAD: http://www.cicad.oas.org/lavado_activos/ esp/BAIRESpaises/declaracion-bsas.htm.

Constitución Política de Colombia (1991). Artículo 29. Asamblea Nacional Constituyente.

Corte Constitucional (23 de mayo de 2007). Sentencia C-396. Expediente D-6482. M. P. Marco Gerardo Monroy Cabra.

Corte Constitucional (3 de marzo de 2010). Sentencia C-144. Expediente D-7832. M. P. Juan Carlos Henao Pérez.

Corte Constitucional (22 de noviembre de 2005). Sentencia C-1194. Expediente D-5727. M. P. Marco Gerardo Monroy Cabra.

Corte Suprema de Justicia. Sala de Casación Penal (19 de enero de 2005). Proceso 21044. M. P. Jorge Luis Quintero Milanés.

Corte Suprema de Justicia, Sala de Casación Penal (9 de marzo de 2006). Proceso 22179. M. P. Jorge Luis Quintero Milanés.

Corte Suprema de Justicia, Sala de Casación Penal (24 de enero de 2007). Proceso 25219. M. P. Yesid RAMíREZ Bastidas.

Corte Suprema de Justicia, Sala de Casación Penal (9 de abril de 2008). Proceso 23754. M. P. Sigifredo Espinosa PÉrez.

Corte Suprema de Justicia, Sala de Casación Penal (11 de marzo de 2009). Proceso 26144. M. P. Alfredo Gómez QuinTero.

Corte Suprema de Justicia, Sala de Casación Penal (2 de febrero de 2011). Proceso 27144. M. P. Jorge Luis Quintero Milanés.

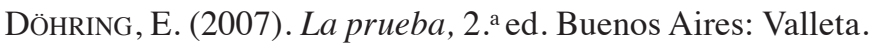

DurÁn Climent, C. (2011). La prueba penal. Tomo I, 2. a ed. Valencia: Tirant Lo Blanch.

Ferrajoli, L. (2009). Derecho y razón: Teoría del garantismo penal, 9. a ed. Madrid: Trotta. 
Ferrajoli, L. (2010). Derechos y garantías: La ley del más débil, 7. ${ }^{\mathrm{a}}$ ed. Madrid: Trotta.

FERRER BELTRÁN, J. (2007). La valoración racional de la prueba. Madrid: Marcial Pons.

Ferrer Beltrán, J. (2013). "La prueba es la libertad pero no tanto: Una teoría de la prueba cuasibenthamiana”, en C. VÁZQUEZ (ed.). Estándares de prueba y prueba científica: Ensayos de epistemología jurídica. Madrid: Marcial Pons.

Florián, Eugenio (1982). De las prueba penales. Bogotá: Temis.

GÁlvez Bravo, R. (2014). Los modus operandi en las operaciones de blanqueo de capitales. Barcelona: Bosch.

García LóPez, S. (2008). Agencia Estatal de Administración Tributaria (España). Blanqueo de capitales evolución del delito subyacente. Cuadernos de Formación. Colaboración 5/08. Volumen 5 [en línea]. Madrid (España): Instituto de Estudios Fiscales: Recuperado de la página web del Instituto: http://www.ief.es/documentos/ recursos/publicaciones/revistas/cuadernos_formacion/052008/Colab_05_08.pdf.

Gómez Colomer, J. L. (2010). “El objeto del proceso”, en J. L. Gómez Colomer, J. Moreno Aroca, A. Montón Redondo y S. Barona Vilar. Derecho Jurisdiccional III. Proceso Penal, 18. a ed. Valencia: Tirant lo Blanch.

Granados Peña, J. y Morris Liévano, M. M. (2015a). Principios rectores y garantías fundamentales. Sistema penal acusatorio, Tomo I. Bogotá: Ediciones Jurídicas Andrés Morales.

Granados Peña, J. y Morris LiÉvano, M. M. (2015b). Principios rectores y garantías fundamentales. Sistema penal acusatorio. Tomo II. Bogotá: Ediciones Jurídicas Andrés Morales.

Guerrero Peralta, O. J. (2011). Fundamentos teóricos constitucionales del nuevo proceso penal, 2. ${ }^{a}$ ed. Bogotá: Ediciones Nueva Jurídica.

Hernández Marín, R. (2008). Las obligaciones básicas de los jueces. Madrid: Marcial Pons.

Hernández Quintero, H. A. (2008). “La problemática del delito previo frente al lavado de activos", en H. A. Hernández Quintero (dir. GedPE). Cuadernos de derecho penal económico, n. ${ }^{\circ}$ 2. Ibagué: Universidad de Ibagué. 
Hernández Quintero, H. A. (2011). "Lavado de activos: Características generales y su tipificación penal en Colombia”, en H.A. HERnÁNDEZ QuINTERo (dir. GEDPE). Cuadernos de derecho penal económico, n. ${ }^{\circ}$. Ibagué: Universidad de Ibagué.

Hernández Quintero, H. A. (2013). Los delitos económicos en la actividad financiera, $6 .^{\mathrm{a}}$ ed. Bogotá: Grupo Editorial Ibáñez.

Hinostroza Pariachi, C. (2009). El delito de lavado de activos: Delito fuente. Lima: Editora jurídica Grijley.

IbáÑez, P. A. (2009). Prueba y convicción judicial en el proceso penal. Buenos Aires: Hammurabi.

Jauchen, E. M. (2005). Derechos del imputado. Buenos Aires. Rubinzal-Culzoni.

Jauchen, E. M. (2012).Tratado de Derecho procesal penal. Tomo I. Buenos Aires: Rubinzal-Culzoni.

LEY 1121 DE 2006. Por la cual se dictan normas para la prevención, detección, investigación y sanción de la financiación del terrorismo y otras disposiciones. Diario Oficial 46497. Colombia: Congreso de la República. 30 de diciembre, 2006. Artículo 17.

LEY 1453 DE 2011. Por medio de la cual se reforma el Código Penal, el Código de Procedimiento Penal, el Código de Infancia y Adolescencia, las reglas sobre extinción de dominio y se dictan otras disposiciones en materia de seguridad. Diario Oficial 48110. Colombia: Congreso de la República, 24 de junio, 2011. Artículo 42.

LEY 1762 DE 2015. Por medio de la cual se adoptan instrumentos para prevenir, controlar y sancionar el contrabando, el lavado de activos y la evasión fiscal. Diario Oficial 49565. Colombia: Congreso de la República, 6 de julio, 2015. Artículo 11.

Maier, J. B. J. (2012). Derecho Procesal Penal I: Fundamentos, 2. a ed. Buenos Aires: Editores del Puerto.

Montero Aroca, J. (1997). Principios del proceso penal: Una explicación basada en la razón. Valencia: Tirant lo Blanch Alternativa.

Morales Rivera, R. (2011). La prueba: Un análisis racional y práctico. Valencia: Marcial Pons.

Muñoz Conde, F. (2007). Derecho penal. Parte general, 7. ${ }^{\text {e }}$ ed. Valencia: Tirant Lo Blanch. 
Nieva Fenol, J. (2012). Fundamentos de Derecho procesal. Buenos Aires: Editorial $\mathrm{B}$ de $\mathrm{F}$.

PARRA QUIJANO, J. (2008). Manual de derecho probatorio: La prueba en los procedimientos civil, penal (ordinario y militar), laboral, canónico, contencioso-administrativo y en el derecho comparado, $16 .^{\text {a }}$ ed. Bogotá: Librería Ediciones del Profesional.

PASTOR, D. R. (2012). Tendencias hacia una aplicación más imparcial del derecho penal. Buenos Aires: Hammurabi.

Schiavo, N. (2013). Valoración racional de la prueba en materia penal: Un necesario estándar mínimo para la habilitación del juicio de verdad. Buenos Aires: Editores del Puerto.

Sintura, F.; MartíneZ, W. y Quintana, F. (2011). Sistemas de prevención de lavado de activos y financiación del terrorismo. Bogotá: Legis.

SolóRZANo, C. A. (2013). Sistema acusatorio y técnicas del juicio oral, 4. ${ }^{\text {a }}$ ed. Bogotá: Ediciones Nueva Jurídica.

TARUfFo, M. (2005). La prueba de los hechos, 2. ${ }^{\text {a }}$ ed. Madrid: Trotta.

TARuffo, M. (2013). La prueba. Madrid: Marcial Pons.

UNIDAD DE INFORMACIÓN Y ANÁLISIS FINANCIERO, UIAF (2014). Sistema Nacional ALA/ CTF [en línea]. Recuperado de la página oficial de la UIAF: https://www.uiaf.gov.co/ sistema_nacional_ala_cft/lavado_activos.

URBANO MARTínez, J. J. (2012). La nueva estructura probatoria del proceso penal: Hacia una propuesta de fundamentación del sistema acusatorio, 2. a ed. Bogotá: Ediciones Nueva Jurídica.

Vélez Mariconde, A. (1969). Derecho procesal penal. Buenos Aires: Lerner.

Vélez Mariconde, A. (1981). Derecho procesal penal. Córdoba: Lerner.

VervaELE, J. (2011). “Delincuencia económica y lavado de activos ¿un nuevo paradigma en el sistema penal?”, en H. A. Hernández Quintero (dir. GEDPE). Lavado de activos y delitos afines. Cuadernos de Derecho Penal Económico, n. ${ }^{\circ} 5$, mayo de 2011. Ibagué: Universidad de Ibagué. 